\title{
Decisions of Low Carbon Supply Chain with Corporate Social Responsibility and Fairness Concerns
}

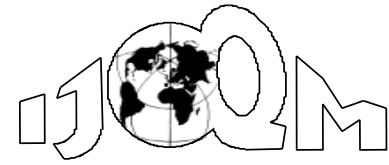

DOI: $10.46970 / 2021.27 .4 .3$

Volume 27, Number 4

December 2021, pp. 337-360

\author{
Li-Hong He \\ Yong-Kang Leng \\ Lanzhou University \\ (helh@1zu.edu.cn) \\ (lengyk19@1zu.edu.cn) \\ Sheng-Nan Pan \\ Jiaozuo University \\ (695387055@qq.com)
}

To compare the decisions of corporate social responsibility (CSR) and fairness concerns in a low carbon supply chain (LCSC), decentralized decision making with and without retailer's fairness concerns are constructed based on manufacturer's CSR. The possibility of LCSC coordination is explored by a costsharing contract. It is shown that the manufacturer's CSR contributes to LCSC. Although his profit is reducing, the utility and consumer surplus are increasing. The retailer's fairness concerns threaten the development of LCSC by reducing the manufacturer's low-carbon invest. Furthermore, cost-sharing contracts can be a coordinating parameter in the LCSC with retailer's fairness concerns.

Keywords: Low Carbon Supply Chain, Corporate Social Responsibility, Fairness Concerns, Cost Sharing Contract

\section{Introduction}

With the development of the industrial economy and the dramatic increase in the number of people, carbon dioxide emissions are being emitted more and more, which prompts growing awareness of environmental degradation. For companies, there are three forces gaining the pressure of businesses to improve their environmental management: staying ahead of regulations, stakeholder activism, competitive pressures, thus investment in green products is one of the best practices of environmental management. For consumers, they are more motivated to buy products from companies with good environmental performance (Grimmer and Bingham, 2013), in addition to the fact that they expect companies to take the lead in environmental protection (Bonini and Oppenheim, 2008). For the governments, they are motivating companies to fulfill better corporate social responsibility (CSR) for the purpose of protecting the environment through various measures, such as strengthening regulation, financial subsidies, and tax breaks.

Driven by pressure from consumers, the environment and government, enterprises are stimulated to consider their CSR.Though increasing the cost of enterprises and compromising their profits, environmental degradation poses challenges as well as opportunities, where companies can develop sustainable offerings or redesign existing ones to become eco-friendly to reap a competitive advantage (Robert and Klassen, 1996; Lash and Wellington, 2007; Nidumolu et al., 2009; Liu et al., 2012). As a consequence, more and more corporations, no matter what size, are taking into account a green approach to managing their supply chains. (Rao, 2002; Chitra, 2007; Seuring, 
2013). For example, BYD is pioneering manufacturer in China, which spans four industries: automotive, rail transportation, new energy, and electronics. Issuing CSR report to disclose its philosophy and practices of CSR every year since 2010, BYD has been devoted to reducing energy consumption and carbon emissions during this period, as evidenced by a cumulative investment of more than 100 million USD for investment in environmental protection, equipment renovation and technology promotion. One of the outstanding results achieved is that BYD's new energy vehicle sales still exceeded 200,000 units in 2019 against the backdrop of the fierce competition in the market, which steadily ranked as the Chinese sales champion and was the first for six consecutive years.

Standard theories in economics invoke the assumption that agents are self-interested in their utility functions, which are only determined by their own material rewards. Closer to reality, however, is the fact that members of economic activity usually compare their compensation with that of others, and it is particularly prone for the disadvantaged party to do so (Ding et al., 2013).R\&D in the low carbon supply chain (LCSC) is often invested by manufacturers, who are therefore dominant in the supply chain, with retailers in a position to follow. In this context, combined with the complexity of supply chain management, the construction of LCSC is accompanied by challenges, notably the perception of inequality between the upstream and downstream of the supply chain. On the one hand, the dominant players have the potential to make decisions in their favor because of their strong position, leading to resentment from followers. For example, over the past many years, Walmart has been asking suppliers to lower their supply prices, and in June 2015, Walmart's new warehouse fees and payment plans caused dissatisfaction among suppliers, and the supply chain cooperation was at risk of disintegration. On the other hand, manufacturers must take into account the fairness concerns of retailers to keep the supply chain running smoothly.

Not only are fairness concerns irrational behavior in the supply chain that may threaten the sound development of LCSC, but also suppliers and retailers are often concerned with their own goals rather than the profitability of the entire channel. Considered a "double marginalization" problem, it often leads to poor performance (Spengler, 1950; Nie and Du, 2017). As the leader of a LCSC, the manufacturer is reasonable to propose a contract to improve the efficiency and low carbon level of the supply chain. There are abundant types of contracts in supply chain, from widely applied contracts like revenue sharing contract, cost sharing contract, quantity discount contract, two-part tariff, buyback contracts, and so on (Jeuland and Shugan, 1983; Moorthy, 1987; Ho and Zhang, 2008; Katok and Wu, 2009; Taleizadeh et al., 2018), to coordination mechanism based on Shapley value, nucleolus solution, and equal satisfaction (Zhang and Liu, 2013; Kumar and Sarmah, 2014; Zheng et al., 2019).

While both CSR and fairness issues are critical behaviors in the supply chains, few studies integrate them together, which is what our paper focuses on. A Stackelberg model with manufacturer's CSR and retailer's fairness concerns is constructed under centralized and decentralized decision-making scenarios, respectively, to explore their dual impact on decisions of LCSC. At the same time, a cost sharing contract is designed to align the individual objectives with the overall objectives under 
decentralized decision making, to weaken double marginalization and reduce the passive effect of retailer's fairness concerns.

Contributions of this paper include the following: First, a Stackelberg model with CSR and fairness concerns is constructed to research the interactive impact on LCSC, which presents valuable managerial insights with a perspective that is attuned to reality. Intuitively, we all know that CSR is favorable to LCSC, a fact that has been confirmed by many studies. Still, will manufacturers still be committed to a LCSC if they consider the fairness concerns of retailers? It is difficult to know for sure, which is something that has been poorly studied. Even though fairness concerns of the retailer can hinder the decarbonization of SC, the fact that the manufacturer's CSR has a positive impact on LCSC is revealed in this paper. However, it is also essential to recognize that the positive effect of CSR can only occur under certain conditions.

Second, a simple but useful cost sharing contract is designed to weaken the double marginalization. As a leader of the supply chain striving for decarbonization, the manufacturer invites the retailer to bear the R\&D costs of green products. On the one hand, cost-sharing helps the manufacturer increase his investment in green products and improve the green performance of the supply chain, thus incentivizing consumers with low-carbon preferences to purchase their products and increasing the profitability of the supply chain. On the other hand, cost-sharing contracts are effective in that they not only lead to increased profits for all parties, but also lead to higher low-carbon investments than decentralized decision-making.

The paper is organized as follows: in section 2, a comprehensive review of related studies is presented. Section 3 gives an explanation of the basic model. Section 4 introduces two models and makes comparison of their results. In section 5 , a cost sharing contract is designed and evidenced. In section 6, numerical analysis is presented, and the conclusion in section 7.

\section{Literature Review}

There are three streams of literature research related to our study: CSR in supply chains, supply chains with fairness concerns and cost sharing contract.

\subsection{CSR in Supply Chains}

As all the products or service operating by supply chain is justified only when they are accepted by customers, increasing environmental awareness of consumers exerts pressure on corporations (Seuring and Müller, 2008). Thus, the study of CSR has become an urgent reality due to the deterioration of the environment.

In the research of Goering (2008), and Panda (2014), a company's CSR was expressed through the consumer surplus of its stakeholders. In particular, Panda (2014) pointed out that although a manufacturer's CSR behavior reduces its profit, there is an increase in consumer surplus, which often increases more than the loss of its profit.

Carter and Jennings (2002) empirically investigated the impact of CSR on the decision making of supply chain companies, showing that CSR behavior helps increase customer trust in suppliers and improves supplier performance, thus enhances the competitive position of suppliers. Niet al. (2012) constructed a supply chain in which both upstream and downstream make CSR investment. Two models of simultaneous-move and sequential-move CSR games were considered to explore whether CSR activities are exogenously related and how they can reach a win-win 
model through mutual incentive. Integrating CSR with risk management and environmental decision-making, Cruz (2008) investigated the equilibrium conditions of this dynamic network model with CSR by multicriteria decision-making. Furtherly, Cruz and Wakolbinger (2008) extended this model by measuring the long-term effects of CSR.

\subsection{Fairness Concerns in Supply Chains}

There is a long history of research on fairness, and relative material rewards affecting people's behavior and welfare is a crucial insight.

Fehr and Schmidt (1999) proposed a far-reaching inequity aversion model. They assumed that people are inequity a version, which means that people are willing to move in the direction of more equitable results even at the expense of their own. The utility function they proposed is based on two assumptions, the first is that people experience inequity either when they are worse off or better off, and the second is that material disadvantage makes people suffer more than material advantage.

To explore the effect of fairness in channel coordination, Cui et al. (2007) first incorporated the concept of fairness in a conventional dyadic channel. Based on the inequity a version model proposed by Fehr and Schmidt (1999), Cui et al. (2007) respectively considered the retailer's fairness concerns and both fair-minded manufacturer and retailer. The initial step showed that the retailer motivates to develop a fair outcome in the supply chain because of fairness concerns and a simple wholesale price contract can coordination that channel. Caliskan-Demirag et al. (2010) further considered other nonlinear demand functions such as exponential, elasticity, algebraic, and log it demand, which extended the assumption of a linear demand function in the research of Cui et al. (2007).

Feher and Schmidt (1999), Ho and Su (2009) and Ho et al.(2014) indicated that there are two types of equity issues, one was caused by cooperation, i.e., distributive equity, and the other was called peer-induced fairness, which occurred between competitors. The research developed by Katok and Pavlov (2013) considered three causes of a suboptimal supply chain, i.e., inequality aversion, bounded rationality, and incomplete information. The results showed that inequality aversion explains retailers' behavior most convincingly.

The disadvantaged party is more inclined to compare his or her payoff with others, thus engendering a sense of inequality (Bruyn and Bolton, 2008; Feher and Schmidt, 1999). Considering the impact of both peer-induced fairness and distributional fairness, Pan et al. (2020) built a model with a dominant retailer and two following manufactures in a two-echelon supply chain. More studies assumed that manufacturers dominate the supply chain, a setting that is consistent with most realities, thus the fairness concerns of the followers, i.e. retailers, are more highly considered. Zheng et al. (2019) proposed a model consisting of a manufacturer, a distributor, and a retailer, then incorporated the retailer's fairness concerns into the coordination of this threeechelon supply chain. Pu et al. (2019) built a model with one fairness-sensitive retailer and one manufacturer that dominated the supply chain.

There are also studies considering the fairness concerns of both manufacturers and retailers simultaneously (Du et al., 2014; Li et al., 2018). Li et al. (2018) studied the utilities of the manufacturer and the retailer in a low carbon and closed-loop supply 
chain under stable state and chaotic state. By investigating the news vendor problem for a dyadic supply chain, which considered the fairness concerns of both the supplier and the retailer, Du et al. (2014) further analyzed the effects of fairness concerns of supply chain on the efficiency of the channel. The outcome showed that the double marginalization may be magnified when the supply chain exists fairness concerns, but the coordination contracts can also be successful like fairness-neutral supply chain.

\subsection{Cost Sharing Contract in Supply Chains}

The profit of a decentralized supply chain is always less than that in centralized supply chain, which drives researchers to design different types of contracts to coordinate the supply chain.

Among these contracts in supply chains, cost sharing contract draws the attention of most scholars because of its simplicity and practicality (Bai et al., 2017; Wang et al., 2021; Yang et al., 2017; Zhang and Yu, 2021).Banerjee and Lin (2001) initially proposed a cost sharing contract to realize the optimal size for the upstream and the downstream in a research joint venture situation, and eventually succeeded to coordinate the upstream manufacturer and the downstream retailer. Ghosh and Shah (2015)proposed two models of cost sharing contract to explore their impact on the green supply chains, in which one is that the retailer supported a contract and the other is that the retailer and the manufacturer bargained on the contract. He et al. (2020) built three Stackelberg differential game models to compare the effect of three cost sharing contracts, i.e., not sharing any cost, sharing emission reduction cost, or sharing service cost. Deng et al.(2021)studied whether the cost sharing contract can improve the performance of the local government and enterprises on the investment of lowcarbon technology innovations. In their research, the cost sharing contract means that the government shares its low carbon technology innovation cost with the enterprise. With the differential game model, Liu and Li (2020) designed a cost sharing contract to coordinate the supply chain, in which the low carbon preference of consumers was also integrated. They both concluded that the contract has a good effect to coordinate the supply chain and encourages the members to improve carbon abatement level. Also considering LCSC, Shen et al. (2017) and Wang et al. (2016) compared cost sharing contract to wholesale price contract. Shen et al. (2017) showed that the former has better effect to motivate the manufacturer to adopt clean technology and reduce the optimal wholesale price. Furthermore, the retailer-dominated supply chain and the power-balanced supply chain were both considered by Wang et al. (2016). The result showed that no matter what the power form, the cost sharing contract can coordinate the supply chain.

Specially, there are some studies that considered to coordinate supply chains with fairness concerns. Fehr and Klein (2007) conducted a series of experiments to investigate how fairness concerns affect the actual and optimal choice of contracts. The results showed that contract efficiency decreases significantly as fairness subjects have a large impact on the incentive properties of various contracts. Zhou et al. (2016) presented a one-manufacturer and one-retailer supply chain to explore the effectiveness of the two contracts designed in their paper, and incorporated the fairness concerns into the coordination to explore its impact. Taking three contracts namely wholesale price, revenue sharing contract and cost sharing contract into consideration, Xiao et al. (2020) showed abundant conclusions about the performance of those 
contracts in various situations that when the retailer or manufacturer performs different level of fairness concerns, the effects of the contracts also perform differently. Li et al. (2018) integrated carbon emission reduction (CER) and fairness concerns, which also modeled with fairness-neutral manufacturer and fairness-concerned retailer in a twoechelon supply chain. Though Li et al. (2018) highlighted the impact of retailer's fairness concerns, they neglected to analyze the impact of CSR and fairness concerns in a comprehensive manner, which is refined in our research. In addition, $\mathrm{Li}$ et al. (2018) studied the environment variable by CER, which considered that the manufacturer produces green products, which will cause CER and also green cost. It is worth to be noted that their research only considered the retailer's utility with fairness concerns and the supply chain's utility with fairness concerns, which ignored the consumer surplus. However, in our paper, it is the consumer surplus that presents the concern to CSR of manufacturer.

\section{Model Description}

Including a dominated manufacturer which takes CSR and low carbon investment into account and a followed retailer with or without fairness concerns being considered, the LCSC model is shown in Figure 1. Since consumers in the LCSC have a dual preference for products, concerned with both their price and their low-carbon level, the price of low-carbon products is influenced not only by the baseline retail price of the product, but also by its low-carbon level, which can be featured by

$$
p=a-b q+l \tau
$$

Where $q>0$ is the demand of the low carbon product developed by the manufacturer, $\tau>0$ is the low carbon level, $a>0$ is the benchmark price, $b>0$ and $l>0$ denote the price elasticity coefficients of demand and low carbon level, respectively. Note that $l \tau$ is a price enhancement factor appearing in the linear function, implying that consumers are willing to pay a higher price for a low carbon product.Incorporating an enhancement factor into the price function or demand function is widely used in supply chain models. (Wang et al., 2021; Ray and Jewkes, 2004; Liu et al., 2012).

Emission reduction costs increase with the level of emission reductions, quadratic function is widely used as follows

$c(\tau)=\frac{1}{2} k_{m} \tau^{2}$

where $k_{m}>0$ is the coefficient of low carbon investment.

Based on the above, the profit functions for the manufacturer, the retailer, and the whole supply chain are as follows 


$$
\begin{aligned}
& \pi_{m}=w q-\frac{1}{2} k_{m} \tau^{2} \\
& \pi_{r}=(a-b q+l \tau-w) q \\
& \pi_{c}=(a-b q+l \tau) q-\frac{1}{2} k_{m} \tau^{2}
\end{aligned}
$$

Where $w>0$ is the wholesale price determined by the manufacturer, $\pi_{m}, \pi_{r}$, and $\pi_{c}$ are respectively the profits to the manufacturer, retailer, and the supply chain as a whole. The consumer surplus and the social welfare after the retailer decides the order quantitycan be expressed respectively as

$$
\begin{aligned}
& C S=\int_{p}^{p_{\max }} q d p=\int_{a+l \tau-b q}^{a+l \tau} \frac{a+l \tau-p}{b} d p=\frac{1}{2} b q^{2} \\
& W=(a-b q+l \tau) q-\frac{1}{2} k_{m} \tau^{2}+\frac{1}{2} b q^{2}
\end{aligned}
$$

Where $C S$ denotes consumer surplus, which is the difference between the maximum price consumers are willing to pay and their actual cost, and $W$ represents social welfare, defined as the sum of the profit earned by the firm and consumer surplus.

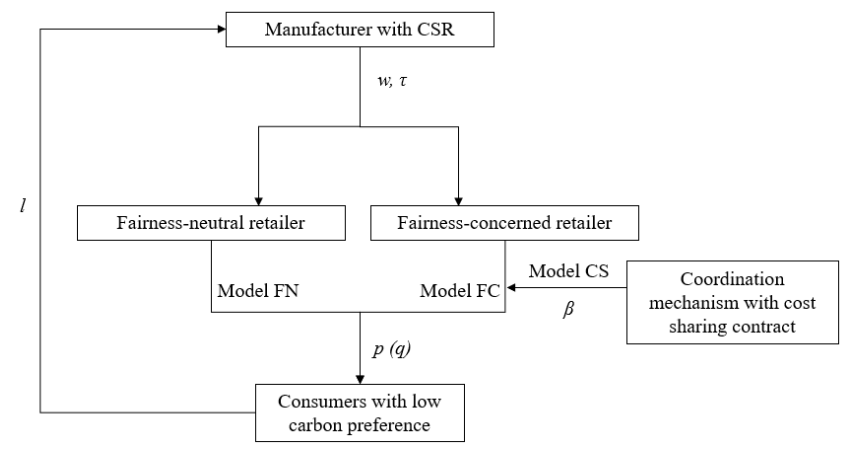

Figure 1 Model Structure of LCSC with Manufacturer's CSR

\section{Decision Makings}

Referring to Panda's definition of CSR(Panda, 2014), the manufacturer's concern for CSR is defined as a concern for consumer surplus, which constitutes the manufacturer's utility function, and the goal it pursues changes from the traditional profit maximization to utility maximization.Denote $t$ as the degree to which the manufacturer is concerned about CSR with $0 \leq t \leq 1$, where $t=0$ means that the 
manufacturer does not care about CSR at all, and $t=1$ means that the manufacturer cares about CSR completely. Only the scenarios with $0<t<1$ will be considered in this study.

\subsection{Model FN: Decentralized Model without Fairness Concerns}

In such a scenario, the retailer does not consider fairness concerns, which pursues maximum profit only. As the leader of the supply chain, the CSR-focused manufacturer first determines $w$ and $\tau$ in accordance with their utility maximization, followed by the retailer determining its product order quantity $q$. Denote $U_{m}$ as the utility obtained by the manufacturer,which can be expressed as follows

$U_{m}=w q-\frac{1}{2} k_{m} \tau^{2}+t \frac{1}{2} b q^{2}$

By background introduction and Hessian Matrix H (See Appedndix A), it can be proven that when $b(4-t) k_{m}-l^{2}>0, \mathrm{H}$ is negative definite, i.e., there are maximum values for $w$ and $\tau$. The optimal decisions can be obtained as shown in Table 1. Thus the following conclusions can be obtained.

Proposition 1. $\frac{\partial \pi_{r}^{F N}}{\partial t}>0, \frac{\partial \pi_{c}^{F N}}{\partial t}>0, \frac{\partial \pi_{m}^{F N}}{\partial t}<0$.

Proof: See Appendix B, and the same for Proposition2-Proposition4.

Proposition 1 demonstrates that whenthe manufacturer's CSR is presented in the supply chain, both the retailer's profit and overall supply chain profit increase as the degree of manufacturer's CSR increases. However, since the manufacturer's CSR calls for it to focus on consumer surplus and share a portion of its profit with consumers, thus, the manufacturer's own profit is caused to decline.

Proposition 2. $\frac{\partial C S^{F N}}{\partial t}>0, \frac{\partial W^{F N}}{\partial t}>0, \frac{\partial U_{m}^{F N}}{\partial t}>0$.

Proposition 2 shows that as the degree of manufacturer's CSR increases, the consumer surplus, social welfare, and the utility ofmanufacturer increase as well.Combined with Proposition 1, it is clear that the manufacturer shares a portion of its profit with consumers, and although his profit diminishes, consumers receive more consumer surplus, which makes the utility of manufacturer remain higher overall. However, given the benefit to shareholders, the manufacturer must limittheirown CSR practices, meaning that $t<1$.

Proposition 3. $\frac{\partial \tau^{F N}}{\partial k_{m}}<0, \frac{\partial w^{F N}}{\partial k_{m}}<0, \frac{\partial q^{F N}}{\partial k_{m}}<0 ; \frac{\partial \tau^{F N}}{\partial l}>0, \frac{\partial w^{F N}}{\partial l}>0, \frac{\partial q^{F N}}{\partial l}>0$. 
Proposition 3 suggests that when the manufacturer has CSR behavior, the equilibrium low-carbon invest level and wholesale price determined by the manufacturer and the equilibrium order quantity determined by the retailer are constrained by the low-carbon cost coefficient on the one hand and positively influenced by consumers' low-carbon preferences on the other. Low-carbon products are more expensive tobe made for the manufacturer (Conrad. 2005), which leads to an increase in the manufacturer's wholesale price. However, the consumers with low carbon preferences are willing to pay higher prices for products with low carbon (TrudelandCotte. 2009.), which is an incentivefor boththe manufacturer to produce and the retailer to sell low carbon products.

\subsection{Model FC: Decentralized Model with Fairness Concerns}

Still dominated by the manufacturer while introducing the retailer's fairness concerns into the LCSC, the decision-making of the manufacturer and retailer are deliberated in this scenario, where the retailer will also pursue utility maximization rather than profit maximization. Referring to the F\&S model proposed by Fehr and Schmidt (1999), the utility functions of the manufacturer and retailer, respectively, are

$$
\begin{aligned}
& U_{m}=w q-\frac{1}{2} k_{m} \tau^{2}+\frac{1}{2} t b q^{2} \\
& U_{r}=\pi_{r}-\mu_{r}\left(\pi_{m}-\pi_{r}\right)
\end{aligned}
$$

Integrating the profit functions of the retailer and the manufacturer yields the utility function of retailer as

$$
U_{r}=q(a-b q-w+l \tau)+\frac{1}{2}\left(2 q(a-b q-2 w+l \tau)+\tau^{2} k_{m}\right) \mu_{r}
$$

The optimal decisions can be obtained under the condition $b k_{m}\left(1+2 \mu_{r}\right)\left(4-t+4 \mu_{r}-2 t \mu_{r}\right)-l^{2}\left(1+\mu_{r}\right)^{2}>0$ by the backward introduction and Hessian matrix (See Appendix A), as demonstrated in Table 1. Then we can get the following conclusions.

Proposition 4. $\frac{\partial \tau^{F C}}{\partial t}>0, \frac{\partial q^{F C}}{\partial t}>0, \frac{\partial w^{F C}}{\partial t}<0 ; \frac{\partial C S^{F C}}{\partial t}>0, \frac{\partial W^{F C}}{\partial t}>0$

Proposition 4 indicates that the impact of manufacturer's CSR behavior on the supply chain is positive even in the presence of retailer'sfairnessconcerns. This is evidenced by the fact that as the manufacturer's CSR level increases, both the manufacturer's investment level of low carbon and the retailer's order quantity increase, and the manufacturer's wholesale price of the product decreases. The reduction in wholesale price reduces the retail price of the product and increases consumer surplus and social welfare. 
Proposition 5. $\frac{\partial U_{m}^{F C}}{\partial \mu_{r}}<0, \frac{\partial \tau^{F C}}{\partial \mu_{r}}<0, \frac{\partial w^{F C}}{\partial \mu_{r}}<0$; under the condition of

$$
t b k_{m}<l^{2}<\frac{9}{4} t b k_{m}, \frac{\partial C S^{F C}}{\partial \mu_{r}}>0 \text { for } \mu_{r} \in\left(0, \frac{l-\sqrt{t b k_{m}}}{2 \sqrt{t b k_{m}}-l}\right), \text { and } \frac{\partial C S^{F C}}{\partial \mu_{r}}<0
$$

when $\mu_{r} \in\left(\frac{l-\sqrt{t b k_{m}}}{2 \sqrt{t b k_{m}}-l}, 1\right)$.

Proof. See Appendix C.

It can be concluded from Proposition 5 that the supply chain decarbonization is hamstrung by fairness concerns. Although low-carbon inputs enhance the overall benefits of the supply chain, the retailer's fairness concerns are not spared to lose her own benefit in pursuit of equity, which is manifested in this scenario in the reduction of decarbonization, i.e., with the increase in the coefficient ofretailer's fairness concerns, the manufacturer's low-carbon input decreases subsequently.

In addition, the retailer's fairness concerns also lead to lower wholesale prices for the manufacturer. Although the manufacturer is willing to reduce his wholesale price to increase the consumer surplus, as intentioned before, the manufacturer will not share too much of his benefit with the retailer and consumers because of the shareholders. More specifically, fairness concerns of the retailer lead to lower wholesale price for the manufacturer, who decides that the wholesale price should be reduced in order to maintain the supply chain development when the retailer's fairness concerns factor is maintained within a certain range. An unexpected benefit for consumers appears as a result where by they receive a higher consumer surplus owing to the reduced wholesale price.

However, excessive retailer's fairness concerns will trigger the breakdown of the supply chain, provoking the manufacturer into terminating the cooperation with the retailer, and the consumer will also suffer losses, as expressed in the decrease of consumer surplus with the increase of retailer's fairness concerns.

\subsection{Comparison of FN and FC models}

To illustrate the impact of fairness concerns from the retailer, this part compares the optimal decisions of the last two sections, which should satisfy the range of $\left(1+2 \mu_{r}\right)\left(4-t+4 \mu_{r}-2 t \mu_{r}\right) b k_{m}-\left(1+\mu_{r}\right)^{2} l^{2}>0$.

Conclusion 1. $\tau^{F C}<\tau^{F N}, q^{F C}<q^{F N}, w^{F C}<w^{F N}, U_{m}^{F C}<U_{m}^{F N}$. Proof. See Appendix D

Proposition 5 gives the variation of some factors with the retailer's fairness concerns, confirming the negative impact of fairness concerns on the supply chain, which is more directly illustrated by Conclusion 1, i.e., the low carbon input, order quantity, and wholesale price in the supply chain are inferior to those before fairness concerns.

The retailer's fairness concerns lower the manufacturer's wholesale price, but 
instead of increasing its order quantity to compensate the manufacturer, the retailer also lowers its order quantity, further exacerbating the manufacturer's loss. All these actions lead to manufacturer's inability to afford the huge costs of R\&D of low-carbon products, which may eventually make the LCSC unsustainable and the supply chain less competitive.

Table 1 Optimal Decisions of Model FN and Model FC

\begin{tabular}{|c|c|c|}
\hline Variables & Model FN & Model FC \\
\hline$\tau$ & $\frac{a l}{(4-t) b k_{m}-l^{2}}$ & $\frac{a l\left(1+\mu_{r}\right)^{2}}{b k_{m}\left(1+2 \mu_{r}\right)\left(4+4 \mu_{r}-t-2 t \mu_{r}\right)-l^{2}\left(1+\mu_{r}\right)^{2}}$ \\
\hline$w$ & $\frac{a b k_{m}(2-t)}{(4-t) b k_{m}-l^{2}}$ & $\frac{a b k_{m}\left(1+\mu_{r}\right)\left(2+2 \mu_{r}-t-2 t \mu_{r}\right)}{b k_{m}\left(1+2 \mu_{r}\right)\left(4+4 \mu_{r}-t-2 t \mu_{r}\right)-l^{2}\left(1+\mu_{r}\right)^{2}}$ \\
\hline$q$ & $\frac{a k_{m}}{(4-t) b k_{m}-l^{2}}$ & $\frac{a k_{m}\left(1+\mu_{r}\right)\left(1+2 \mu_{r}\right)}{b k_{m}\left(1+2 \mu_{r}\right)\left(4+4 \mu_{r}-t-2 t \mu_{r}\right)-l^{2}\left(1+\mu_{r}\right)^{2}}$ \\
\hline$\pi_{r}$ & $\frac{a^{2} b k_{m}^{2}}{\left((4-t) b k_{m}-l^{2}\right)^{2}}$ & $\frac{a^{2} b k_{m}^{2}\left(1+\mu_{r}\right)\left(1+2 \mu_{r}\right)\left(1-\mu_{r}\left(t-5+2 \mu_{r}(t-2)\right)\right)}{\left(b k_{m}\left(1+2 \mu_{r}\right)\left(4+4 \mu_{r}-t-2 t \mu_{r}\right)-l^{2}\left(1+\mu_{r}\right)^{2}\right)^{2}}$ \\
\hline$\pi_{m}$ & $\frac{a^{2} k_{m}\left(2(2-t) b k_{m}-l^{2}\right)}{2\left((4-t) b k_{m}-l^{2}\right)^{2}}$ & $\frac{a^{2} k_{m}\left(1+\mu_{r}\right)^{2}\left(2 b k_{m}\left(1+2 \mu_{r}\right)\left(2+2 \mu_{r}-t-2 t \mu_{r}\right)-l^{2}\left(1+\mu_{r}\right)^{2}\right)}{2\left(b k_{m}\left(1+2 \mu_{r}\right)\left(4+4 \mu_{r}-t-2 t \mu_{r}\right)-l^{2}\left(1+\mu_{r}\right)^{2}\right)^{2}}$ \\
\hline$\pi_{c}$ & $\frac{a^{2} k_{m}\left(2(3-t) b k_{m}-l^{2}\right)}{2\left((4-t) b k_{m}-l^{2}\right)^{2}}$ & $\frac{a^{2} k_{m}\left(1+\mu_{r}\right)\left(2 b k_{m}\left(1+2 \mu_{r}\right)^{2}\left(3-t-(2 t-3) \mu_{r}\right)-l^{2}\left(1+\mu_{r}\right)^{3}\right)}{2\left(b k_{m}\left(1+2 \mu_{r}\right)\left(4+4 \mu_{r}-t-2 t \mu_{r}\right)-l^{2}\left(1+\mu_{r}\right)^{2}\right)^{2}}$ \\
\hline$U_{r}$ & $\frac{a^{2} k_{m}\left((7-2 t) b k_{m}-l^{2}\right)}{2\left((4-t) b k_{m}-l^{2}\right)^{2}}$ & $\frac{a^{2} k_{m}\left(1+\mu_{r}\right)^{3}\left(l^{2} \mu_{r}\left(1+\mu_{r}\right)+2 b k_{m}\left(1+2 \mu_{r}\right)^{2}\right)}{2\left(b k_{m}\left(1+2 \mu_{r}\right)\left(4+4 \mu_{r}-t-2 t \mu_{r}\right)-l^{2}\left(1+\mu_{r}\right)^{2}\right)^{2}}$ \\
\hline$U_{m}$ & $\frac{a^{2} b k_{m}^{2}}{2\left((4-t) b k_{m}-l^{2}\right)^{2}}$ & $\frac{a^{2} k_{m}\left(1+\mu_{r}\right)^{2}}{2\left(b k_{m}\left(1+\mu_{r}\right)^{2}\left(1+2 \mu_{r}\right)^{2}\right.}$ \\
\hline$a_{m}^{2} k_{m}\left(b k_{m}\left(1+2 \mu_{r}\right)\left(4+4 \mu_{r}-t-2 t \mu_{r}\right)-l^{2}\left(1+\mu_{r}\right)^{2}\right)^{2}$ \\
\hline
\end{tabular}

\section{Model CS: Coordination with Cost Sharing Contract}

Since the low carbon innovation of the manufacturer creates a positive externality for down stream firms, upstream firms may decide to internalize this externality by inviting the down stream firm, i.e., the retailer, to share the R\&D costs

Assume that the retailer shares the low-carbon product $R \& D$ costs for the manufacturer and the sharing ratio is $\beta$, where $0<\beta<1 . C_{m}(\tau)$ And $C_{r}(\tau)$ are denoted as the manufacturer's and retailer's R\&D of low carbon products after costsharing, respectively, which are expressed as follows. 


$$
\begin{aligned}
& C_{m}(\tau)=\frac{1}{2}(1-\beta) k_{m} \tau^{2} \\
& C_{r}(\tau)=\frac{1}{2} \beta k_{m} \tau^{2}
\end{aligned}
$$

This yields the profit functions of the manufacturer and retailer respectively as

$$
\begin{aligned}
& \pi_{m}=w q-\frac{1}{2}(1-\beta) k_{m} \tau^{2} \\
& \pi_{r}=(a-b q+l \tau-w) q-\frac{1}{2} \beta k_{m} \tau^{2}
\end{aligned}
$$

Thus, the utility functions of the manufacturer and the retailer are respectively as

$$
\begin{aligned}
& U_{m}=w q-\frac{1}{2}(1-\beta) k_{m} \tau^{2}+\frac{1}{2} t b q^{2} \\
& U_{r}=q(a-b q-w+l \tau)-\frac{1}{2} \beta \tau^{2} k_{m}-(q w-q(a-b q-w+l \tau)- \\
& \left.\frac{1}{2}(1-\beta) \tau^{2} k_{m}+\frac{1}{2} \beta \tau^{2} k_{m}\right) \mu_{r}
\end{aligned}
$$

By backward introduction and Hessian matrix (See Appendix A), the optimal decision can be derived under the condition $(1-\beta)\left(1+2 \mu_{r}\right)\left(4-t+4 \mu_{r}-2 t \mu_{r}\right) b k_{m}-l^{2}\left(1+\mu_{r}\right)^{2}>0$, as illustrated in Table 2, from which the following conclusions can be drawn.

Proposition 6. The supply chain can be coordinated through cost sharing contract when the sharing ratio stays within a reasonable range.

The acceptance of the cost sharing contract by the retailer and manufacturer requires that the profit after the cost-sharing contract should be greater than that before. Denote $\pi_{r}^{C S}$ and $\pi_{m}^{C S}$ the profits of the retailer and manufacturer after the implementation of the cost-sharing contract, implying that $\pi_{r}^{C S}>\pi_{r}^{F C}$ and $\pi_{m}^{C S}>\pi_{m}^{F C}$.

Derive the partial derivatives of $\beta$ for $\pi_{r}^{C S}$ and $\pi_{m}^{C S}$, respectively, and we get

$$
\frac{\partial \pi_{r}^{C S}}{\partial \beta}=a^{2} b l^{2} k_{m}^{2}\left(1+\mu_{r}\right)^{3}\left(1+2 \mu_{r}\right) \times
$$




$$
\begin{aligned}
& \frac{(2-6 \beta+t(2 \beta-1)+(10-18 \beta+(8 \beta-5) t)) \mu_{r}+2(4-6 \beta+t(4 \beta-3)) \mu_{r}^{2}}{\left(b k_{m}(1-\beta)\left(1+2 \mu_{r}\right)\left(4-t+4 \mu_{r}-2 \mu_{r} t\right)-l^{2}\left(1+\mu_{r}\right)^{2}\right)^{3}} \\
& \frac{\partial \pi_{m}^{C S}}{\partial \beta}=\frac{a^{2} l^{2} k_{m}\left(1+\mu_{r}\right)^{4}\left(l^{2}\left(1+\mu_{r}\right)^{2}-b(-1+\beta) k_{m}\left(1+2 \mu_{r}\right)\left(-4+3 t+(-4+6 t) \mu_{r}\right)\right)}{2\left(l^{2}\left(1+\mu_{r}\right)^{2}-b(-1+\beta) k_{m}\left(1+2 \mu_{r}\right)\left(-4+t+2(-2+t) \mu_{r}\right)\right)^{3}}
\end{aligned}
$$

Make $\partial \pi_{r}^{C S} / \partial \beta>0$, then $\beta \in\left(0, R^{C S}\right)$, where

$$
R^{C S}=\frac{b k_{m}\left(1+2 \mu_{r}\right)\left(t+12 \mu_{r}-t \mu_{r}+12 \mu_{r}^{2}-6 t \mu_{r}^{2}\right)+l^{2}\left(1+\mu_{r}\right)^{3}}{b k_{m}\left(1+2 \mu_{r}\right)\left(8-t+28 \mu_{r}-7 t \mu_{r}+20 \mu_{r}^{2}-10 t \mu_{r}^{2}\right)}>0 . \text { When } \beta=0 \text {, }
$$

$\pi_{r}^{C S}=\pi_{r}^{F C}$. Therefore, if $\beta \in\left(0, R^{C S}\right)$, then $\pi_{r}^{C S}>\pi_{r}^{F C}$, i.e., the range $\beta \in\left(0, R^{C S}\right)$ will make the retailer accept the cost sharing contract.

Similarly, we can drive the range in which the manufacturer will accept the cost sharing contract. The range can be expressed by $\beta \in\left(0, M^{C S}\right)$, where

$$
M^{C S}=\frac{b k_{m}\left(1+2 \mu_{r}\right)\left(4-3 t+4 \mu_{r}-6 t \mu_{r}\right)-l^{2}\left(1+\mu_{r}\right)^{2}}{b k_{m}\left(1+2 \mu_{r}\right)\left(4-3 t+4 \mu_{r}-6 t \mu_{r}\right)}>0 .
$$

When $\beta \in\left(0, \min \left\{R^{C S}, M^{C S}\right\}\right)$, the situation that both the retailer and manufacturer gain more profits is available. Thus, the following conclusion can be arrived.

Conclusion 2. When $\beta \in\left(0, \min \left\{R^{C S}, M^{C S}\right\}\right), \frac{\partial w^{C S}}{\partial \beta}>0, \frac{\partial \tau^{C S}}{\partial \beta}>0, \frac{\partial q^{C S}}{\partial \beta}>0$, $\frac{\partial C S^{C S}}{\partial \beta}>0, \frac{\partial W^{C S}}{\partial \beta}>0$.

Proof. See Appendix E.

Some valuable findings can be summarized by combining Proposition 6 and Conclusion 2. In the scenario of model CS, there is a reconcilable interval for LCSC when cost-sharing contract is used. In this interval, the margins of both the manufacturer and the retailer are greater than those before.

The costsharing contract has three positive effects on the supply chain in the following ways. First, since the retailer shares some of the R\&D cost, the manufacturer will invest more capital and have access to produce more eco-friendly products, contributing to a greener supply chain. Second, the retailer's concern for fairness, which reduces their own order quantity and the manufacturer's wholesale price, probably leads to a loss of both with the manufacturer. The cost sharing contract is a great option to improve it.Third, though the wholesale price of the manufacturer is 
reduced, the consumer surplus and social welfare are still increasing with the sharing ratio.

Table 2 Optimal Decisions of Model CS

\begin{tabular}{|c|c|}
\hline Variables & Model CS \\
\hline$\tau$ & $\frac{a l\left(1+\mu_{r}\right)^{2}}{b k_{m}(1-\beta)\left(1+2 \mu_{r}\right)\left(4-t+4 \mu_{r}-2 t \mu_{r}\right)-l^{2}\left(1+\mu_{r}\right)^{2}}$ \\
\hline$w$ & $\frac{a b k_{m}\left(1+\mu_{r}\right)(1-\beta)\left(2-t+2 \mu_{r}-2 t \mu_{r}\right)}{b k_{m}(1-\beta)\left(1+2 \mu_{r}\right)\left(4-t+4 \mu_{r}-2 t \mu_{r}\right)-l^{2}\left(1+\mu_{r}\right)^{2}}$ \\
\hline$q$ & $\frac{a\left(1+\mu_{r}\right)(1-\beta)\left(1+2 \mu_{r}\right)}{b k_{m}(1-\beta)\left(1+2 \mu_{r}\right)\left(4-t+4 \mu_{r}-2 t \mu_{r}\right)-l^{2}\left(1+\mu_{r}\right)^{2}}$ \\
\hline$\pi_{r}$ & $\frac{a^{2} k_{m}\left(1+\mu_{r}\right)\left(2 b k_{m}(1-\beta)^{2}\left(1+2 \mu_{r}\right)\left(1-\mu_{r}\left(t-5+2 \mu_{r}(t-2)\right)\right)-l^{2} \beta\left(1+\mu_{r}\right)^{3}\right)}{2\left(b k_{m}(1-\beta)\left(1+2 \mu_{r}\right)\left(4-t+4 \mu_{r}-2 t \mu_{r}\right)-l^{2}\left(1+\mu_{r}\right)^{2}\right)^{2}}$ \\
\hline$\pi_{m}$ & $\frac{a^{2}(1+\beta) k_{m}\left(1+\mu_{r}\right)^{2}\left(2 b k_{m}(1-\beta)\left(1+2 \mu_{r}\right)\left(2-t+2 \mu_{r}-2 t \mu_{r}\right)-l^{2}\left(1+\mu_{r}\right)^{2}\right)}{2\left(b k_{m}(1-\beta)\left(1+2 \mu_{r}\right)\left(4-t+4 \mu_{r}-2 t \mu_{r}\right)-l^{2}\left(1+\mu_{r}\right)^{2}\right)^{2}}$ \\
\hline$\pi_{c}$ & $\frac{a^{2} k_{m}\left(1+\mu_{r}\right)\left(2 b k_{m}(1-\beta)^{2}\left(1+2 \mu_{r}\right)^{2}\left(3-t+3 \mu_{r}-2 t \mu_{r}\right)-l^{2}\left(1+\mu_{r}\right)^{3}\right)}{2\left(b k_{m}(1-\beta)\left(1+2 \mu_{r}\right)\left(4-t+4 \mu_{r}-2 t \mu_{r}\right)-l^{2}\left(1+\mu_{r}\right)^{2}\right)^{2}}$ \\
\hline$U_{r}$ & $\frac{a^{2} k_{m}\left(1+\mu_{r}\right)^{3}\left(2 b(1-\beta)^{2} k_{m}\left(1+2 \mu_{r}\right)^{2}-l^{2}\left(1+\mu_{r}\right)\left(\beta+(2 \beta-1) \mu_{r}\right)\right)}{2\left(b k_{m}(1-\beta)\left(1+2 \mu_{r}\right)\left(4-t+4 \mu_{r}-2 t \mu_{r}\right)-l^{2}\left(1+\mu_{r}\right)^{2}\right)^{2}}$ \\
\hline$U_{m}$ & $\frac{a^{2} k_{m}(1-\beta)\left(1+\mu_{r}\right)^{2}}{2\left(b k_{m}(1-\beta)\left(1+2 \mu_{r}\right)\left(4-t+4 \mu_{r}-2 t \mu_{r}\right)-l^{2}\left(1+\mu_{r}\right)^{2}\right)}$ \\
\hline$C S$ & $\frac{a^{2} b k_{m}^{2}(1-\beta)^{2}\left(1+\mu_{r}\right)^{2}\left(1+2 \mu_{r}\right)^{2}}{2\left(b k_{m}(1-\beta)\left(1+2 \mu_{r}\right)\left(4-t+4 \mu_{r}-2 t \mu_{r}\right)-l^{2}\left(1+\mu_{r}\right)^{2}\right)^{2}}$ \\
\hline$W$ & $\frac{a^{2} k_{m}\left(1+\mu_{r}\right)\left(b k_{m}(1-\beta)^{2}\left(1+2 \mu_{r}\right)^{2}\left(4-t+4 \mu_{r}-2 t \mu_{r}\right)-l^{2}\left(1+\mu_{r}\right)^{3}\right)}{2\left(b k_{m}(1-\beta)\left(1+2 \mu_{r}\right)\left(4-t+4 \mu_{r}-2 t \mu_{r}\right)-l^{2}\left(1+\mu_{r}\right)^{2}\right)^{2}}$ \\
\hline
\end{tabular}

\section{Numerical Analysis}

To further demonstrate the effect of the cost-sharing contract and the impact of the manufacturer's CSR degree $t$ and retailer's sharing ratio $\beta$, three numerical examples are presented in this section. In particular, model FN, FCand CS are all illustrated in this part, and the specific parameters are assumed for all the scenarios as follows: $\mu_{r}=0.5, \beta \in(0,1), t \in(0,1), a=100, b=10, k_{m}=6, l=3$.

It is persuasive that the cost sharing contract stimulates the supply chain cooperation 
to some extent, which has been given out by combining Proposition 6 and Conclusion 1 , and the numerical results are illustrated in Figure2.

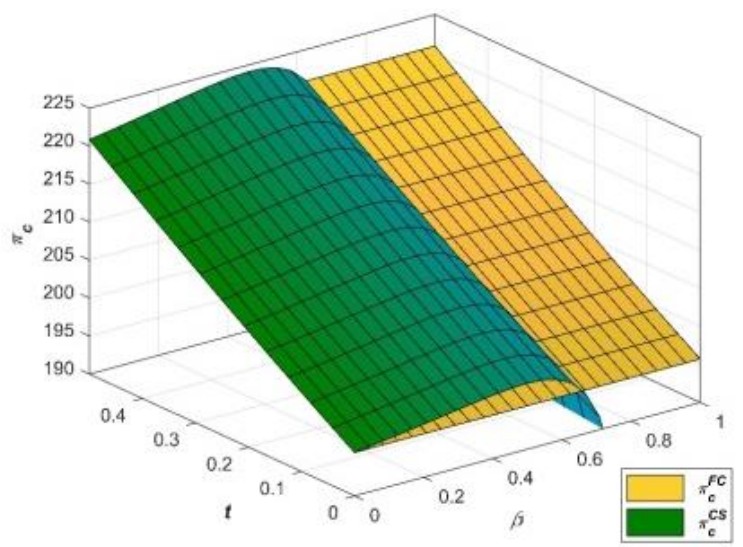

Figure 2 The Impact of $t$ and $\beta$ on the Profit of overall Supply Chain

It is known from proposition 6 that regardless of the degree of the manufacturer's CSR $t$, the manufacturer's profit and retailer's profit under the cost sharing contract are greater than the pre-cost-sharing profit in the range $\beta \in\left(0, \min \left\{R^{C S}, M^{C S}\right\}\right)$. Therefore, the overall supply chain profit under the cost-sharing contract is greater than the pre-cost-sharing profit. Taking Figure 2 as an example, the overall profit of the supply chain increases when the manufacturer's CSR degree is constant and the cost-sharing rate is within a reasonable range. However, once the cost-sharing rate is beyond the range, the overall profit of the supply chain will suffer different degrees of decline until it is less than the profit before the cost sharing contract, which also means that the supply chain cooperation then breaks down. Also, Proposition 4, which demonstrates that the impact of manufacturer's CSR on the supply chain remains positive even under fairness concerns of the retailer, is confirmed by Figure 2, which shows that the overall profit of the supply chain increases with $t$.

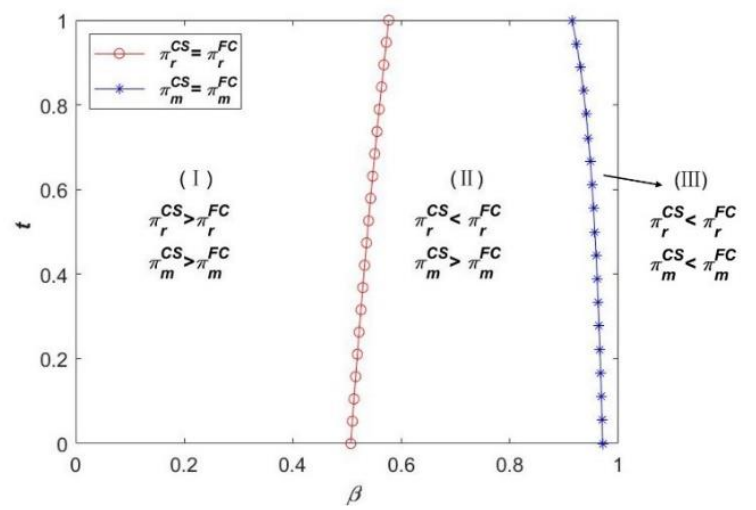

Figure 3 The impact of CSR and sharing ratio on the profit of manufacturer and retailer 
The cost sharing contract and CSR interact to develop the supply chain, which will obtain more profit only when CSR degree is relatively high and the sharing ratio is in a reasonable range. On the contrary, the supply chain will not achieve higher profit if the CSR degree is high but the sharing ratio is beyond the range.

Figure 3 depicts the trend of manufacturer's and retailer's profits under the joint effect of CSR and the cost sharing contract.

In Figure 3, the curve with'*' represents $\pi_{m}^{C S}=\pi_{m}^{F C}$, which is expressed by $\beta=\frac{131072000 t^{3}-963686400 t^{2}+2260696320 t-167835677}{320\left(409600 t^{3}-3028800 t^{2}+7166898 t-5298507\right)}$, and the curve with 'o' represents $\pi_{r}^{C S}=\pi_{r}^{F C}$, which is expressed by $\beta=\frac{102400 t^{2}-1246080 t+2762613}{409600 t^{2}-3054720 t+5451840}$. The image is divided into three regions by these two curves, satisfying $\pi_{r}{ }^{C S}>\pi_{r}{ }^{F C}$ and $\pi_{m}^{C S}>\pi_{m}^{F C}$ in region I , $\pi_{r}^{C S}<\pi_{r}^{F C}$ and $\pi_{m}^{C S}>\pi_{m}^{F C}$ in region II , $\pi_{r}^{C S}<\pi_{r}^{F C}$ and $\pi_{m}^{C S}<\pi_{m}^{F C}$ in region III. It is evident from Figure 3 that the condition $\pi_{r}^{C S}>\pi_{r}^{F C}$ and $\pi_{m}^{C S}>\pi_{m}^{F C}$ are definitely satisfied within the range of region I , in which the retailer is satisfied with the cost sharing contract, and the manufacturer's profit will increase as a result. As the degree of manufacturer's CSR $t$ increases, on the one hand, the manufacturer is willing to make the cost sharing contract effective through a lower sharing ratio $\beta$, and on the other hand, the retailer is agreeable to accept a higher sharing ratio. It suggests that with the concerted efforts of CSR and the cost sharing contract, the manufacturer and the retailer take more consider is on of the other's interests, rather than making decisions only with the goal of maximizing its own profit, which is more conducive to the cooperation between the two parties.

Combining Figure 2, Figure 3 and Proposition 6, it is available that the supply chain achieves the goal of coordination and optimization under the cost sharing contract compared to the pre-sharing. For the further purpose of driving the impact of the cost sharing contract on the manufacturer's low carbon effort, there is no harm in letting $t=0.3$ at random. Thus, the range of $\beta$ can be calculated as $(0,0.524)$. Within this range, the impact of the sharing ratio on manufacturer's low-carbon inputs is illustrated in Figure 4.

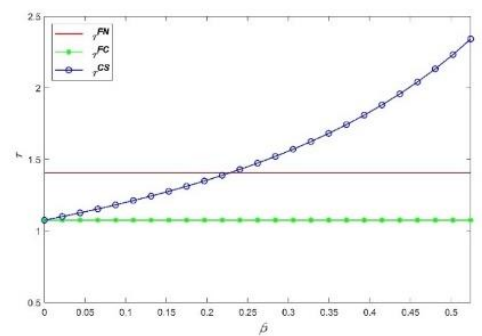

Figure 4 The Impact of Sharing Ratio on Low Carbon Input 
Conclusion 2 is verified by Figure 4, which indicates that the fairness-concerned behavior of the retailer is an irrational behavior that reduces the manufacturer's low carbon inputs. However, the combination of Figure 4 and Conclusion 2 shows that a retailer's sharing of manufacturer's low-carbon cost can increase the degree of manufacturer's low-carbon efforts. Even with the presence of retailer's fairness concerns, it is even possible to achieve a coordinated degree of manufacturer's lowcarbon effort greater than that under retailer's fairness neutrality.

\subsection{Summary}

\section{Conclusion}

Integrating manufacturer's CSR and retailer's fairness concerns, a Stackelberg model is considered to study the dual impact of both factors in the LCSC. A cost sharing contract is designed to mitigate the double marginalization and has been proven effective.

Here are a few notable conclusions: (1) Decision-making of the manufacturers is also affected by their own behavior, i.e., CSR, if the retailer's fairness concerns are not taken into account, with the increasing CSR degree, the level of low carbon investment decided by the manufacturer and the order quantity decided by the retailer will increase and the wholesale price will decrease. (2) When the retailer are concerned about their fairness, the manufacturer will reduce wholesale price to compensate for this unfair mentality of retailer, but also reduce low-carbon invests in their products because of this retailer's behavior. (3) The cost sharing contract can realize the coordination of LCSC with retailer's fairness concerns. When the sharing ratio is within a certain range, the cost sharing contract can facilitate the development of LCSC and have a positive impacton consumer surplus and social welfare. The sharing ratio has a catalytic effect on manufacturer's low-carbon inputs, allowing for a coordinated low-carbon investment that is even greater than the low-carbon investment when retailer is fairnessneutral.

\subsection{Management Insights}

Management insights can be provided from the above results as follows.

(1) With growing awareness of low carbon and higher demands on environmental protection of consumers, companies are aroused to put CSR on their agenda, which is not only a challenge but also an available opportunity. On the one hand, enterprises that cannot keep up with the trend of low carbon and fail to achieve low carbon reform will be phased out of the market; on the other hand, those who conduct low carbon $\mathrm{R} \& \mathrm{D}$ and make efforts to transform will be recognized by consumers and gain more long-term development. Willing to share some of the benefits with consumers to maximize utility, the ultimate goal of a company with CSR is not pursuing profit maximization. Some profits probably are sacrificed in the short term, however, in the long run, CSR will increase a company's investment in low-carbon R\&D and improve the utility of the manufacturer, consumers, and the supply chain as a whole, which is significant for the long-term development of anLCSC.

(2) Even if a manufacturer's CSR behavior is not affected by a retailer's fairness concerns, the retailer should still reduce its level of fairness concerns to lessen the negative impact on the supply chain. When a retailer's fairness concerns are 
considered into the LCSC, series of passive impacts on LCSC are induced.It is worth noting that the retailer'sfairness concerns lead to lower wholesale prices of products, which appear to benefit consumers. However, contrary to CSR behaviors that increase the utility of a manufacturer, the retailer's fairness concerns force the manufacturer to reduce wholesale prices excessively; making manufacturer utility lower. Furthermore, the impediment to supply chain decarbonization from retailer's fairness concerns threatens the sustainability of the supply chain and may ultimately undermine manufacturer's low-carbon efforts.

(3) Fairness concerns have been proven to exist objectively, and retailers should do their best to reduce such behavior, but cannot rigorously require its complete elimination. The manufacturer, as the dominant player in the LCSC, should propose a contract, such as a cost-sharing contract that has been proven to be effective, to reduce the adverse effects on the LCSC of retailer'sfairness concerns and achieve Pare to improvements.

\subsection{Limitations and Future Work}

There are some limitations to this study. First, CSR, which is only considered in the form of CSR of manufacturers for simplicity, should be expanded to the CSR of retailers, as well as CSR of both manufacturers and retailers in future studies. Second, the linear demand function cannot describe the realistic model precisely, a stochastic demand function could be introduced. Third, only the costsharing contractis taken into account at this step, the coordination effects of the contracts in LCSC with fairness concerns can be analyzed base on various contracts, e.g. revenue contracts, quantitydiscount contracts, two-part tariff contracts.

\section{Appendix A. Proof of $\S 4.1, \S 4.2$ and $\S 5$}

\section{Appendices}

$$
\frac{\partial \pi_{r}}{\partial q}=a-2 b q-w+l \tau
$$

The demand of the retailer can be observed by solving $\frac{\partial \pi_{r}}{\partial q}=0$.

$$
q=\frac{a-w+l \tau}{2 b}
$$

Substituting Eq. (A.2) into Eq. (9), we can get

$$
U_{m}=\frac{(a-w+l \tau)(a t+4 w-t w+l t \tau)-4 b \tau^{2} k_{m}}{8 b}
$$

The Hessian Matrix of Eq. (A.3) is $\mathrm{H}=\left[\begin{array}{cc}\frac{-8+2 t}{8 b} & \frac{l(4-t)-l t}{8 b} \\ \frac{l(4-t)-l t}{8 b} & \frac{2 l^{2} t-8 b k_{m}}{8 b}\end{array}\right]$ and obviously $\frac{-8+2 t}{8 b}<0$. It can be proven that when $b(4-t) k_{m}-l^{2}>0, \mathrm{H}$ is 
negative definite, i.e., there are maximum values for $w$ and $\tau$. The optimal decisions can be obtained as shown in Table 1 .

The proofs of $\S 4.2$ and $\S 5$ are similar to $\S 4.1$. It can be derived that when $b k_{m}\left(1+2 \mu_{r}\right)\left(4-t+4 \mu_{r}-2 t \mu_{r}\right)-l^{2}\left(1+\mu_{r}\right)^{2}>0 \quad$ in $\quad \$ 4.2 \quad$ and $(1-\beta)\left(1+2 \mu_{r}\right)\left(4-t+4 \mu_{r}-2 t \mu_{r}\right) b k_{m}-l^{2}\left(1+\mu_{r}\right)^{2}>0$ in $\S 5$, there are maximum values for $w$ and $\tau$. The optimal decisions of $\S 4.2$ and $\S 5$ are also shown in Table 1 and Table 2 respectively.

\section{Appendix B. Proof of Proposition 1-Proposition 4}

Solve the partial derivatives of $\pi_{r}^{F N}, \pi_{c}^{F N}, \pi_{m}^{F N}$ respectively, $\frac{\partial \pi_{r}^{F N}}{\partial t}=\frac{2 a^{2} b^{2} k_{m}^{3}}{\left(b(4-t) k_{m}-l^{2}\right)^{3}} \quad, \quad \frac{\partial \pi_{c}^{F N}}{\partial t}=\frac{a^{2} b^{2}(2-t) k_{m}^{3}}{\left(b(4-t) k_{m}-l^{2}\right)^{3}}$ $\frac{\partial \pi_{m}^{F N}}{\partial t}=\frac{a^{2} b^{2} t k_{m}^{3}}{\left(l^{2}-b(4-t) k_{m}\right)^{3}}$. Because $b(4-t) k_{m}-l^{2}>0$, then $\frac{\partial \pi_{r}^{F N}}{\partial t}>0$ $\frac{\partial \pi_{c}^{F N}}{\partial t}>0, \frac{\partial \pi_{m}^{F N}}{\partial t}<0$ The proofs of Proposition 2 Proposition 4 are similar to Proposition 1.

\section{Appendix C. Proof of Proposition 5}

$$
\begin{aligned}
& \frac{\partial U_{m}^{F C}}{\partial \mu_{r}}=\frac{a^{2} b k_{m}^{2}\left(1+\mu_{r}\right)\left(-2+t+2(-1+t) \mu_{r}\right)}{\left(l^{2}\left(1+\mu_{r}\right)^{2}+b k_{m}\left(1+2 \mu_{r}\right)\right)^{2}} \text {. Because } t-2+2(t-1) \mu_{r}<0, \text { so } \\
& \frac{\partial U_{m}^{F C}}{\partial \mu_{r}}<0 \cdot \frac{\partial \tau^{F C}}{\partial \mu_{r}}=\frac{2 a b l k_{m}\left(1+\mu_{r}\right)\left(t\left(1+2 \mu_{r}\right)-2\left(1+\mu_{r}\right)\right)}{\left(b k_{m}\left(1+2 \mu_{r}\right)\left(4-t+4 \mu_{r}-2 t \mu_{r}\right)-l^{2}\left(1+\mu_{r}\right)^{2}\right)^{2}}, \text { Because } \\
& t\left(1+2 \mu_{r}\right)-2\left(1+\mu_{r}\right)<0, \text { so } \frac{\partial \tau^{F C}}{\partial \mu_{r}}<0 . \\
& \frac{\partial w^{F C}}{\partial \mu_{r}}=-\frac{a b k_{m}\left(b k_{m}\left(8-4 t+t^{2}+4\left(4-3 t+t^{2}\right) \mu_{r}+4\left(2-2 t+t^{2}\right) \mu_{r}^{2}\right)-t l^{2}\left(1+\mu_{r}\right)^{2}\right)}{\left(b k_{m}\left(1+2 \mu_{r}\right)\left(4-t+4 \mu_{r}-2 t \mu_{r}\right)-l^{2}\left(1+\mu_{r}\right)^{2}\right)^{2}}
\end{aligned}
$$

Because

$$
\begin{aligned}
& \left(8-4 t+t^{2}+4\left(4-3 t+t^{2}\right) \mu_{r}+4\left(2-2 t+t^{2}\right) \mu_{r}^{2}\right)-t\left(1+2 \mu_{r}\right)\left(4-t+4 \mu_{r}-2 t \mu_{r}\right), \\
& =2\left(-2+t-2 \mu_{r}+2 t \mu_{r}\right)^{2}>0
\end{aligned}
$$

combined with the condition $t b k_{m}\left(1+2 \mu_{r}\right)\left(4-t+4 \mu_{r}-2 t \mu_{r}\right)-t l^{2}\left(1+\mu_{r}\right)^{2}>0$, 
so $\quad b k_{m}\left(8-4 t+t^{2}+4\left(4-3 t+t^{2}\right) \mu_{r}+4\left(2-2 t+t^{2}\right) \mu_{r}^{2}\right)-t l^{2}\left(1+\mu_{r}\right)^{2}>0 \quad, \quad$ then $\frac{\partial w^{F C}}{\partial \mu_{r}}<0$

$\frac{\partial C S^{F C}}{\partial \mu_{r}}=\frac{a^{2} b k_{m}^{2}\left(1+3 \mu_{r}+2 \mu_{r}^{2}\right)\left(l^{2}\left(1+\mu_{r}\right)^{2}-b t k_{m}\left(1+2 \mu_{r}\right)^{2}\right)}{\left(l^{2}\left(1+\mu_{r}\right)^{2}+b k_{m}\left(1+2 \mu_{r}\right)\left(-4+t+2(-2+t) \mu_{r}\right)\right)^{3}}$. We can get $\mu_{r}<\frac{l-\sqrt{t b k_{m}}}{2 \sqrt{t b k_{m}}-l} \quad$ by solving $\quad \frac{\partial C S^{F C}}{\partial \mu_{r}}>0$ and $\mu_{r}<\frac{l-\sqrt{t b k_{m}}}{2 \sqrt{t b k_{m}}-l} \quad$ by solving $\frac{\partial C S^{F C}}{\partial \mu_{r}}<0$. Combining the condition $\mu_{r} \in(0,1)$, we can derive $t b k_{m}<l^{2}<\frac{9}{4} t b k_{m}$.

\section{Appendix D. Proof of Conclusion 1}

$$
\begin{aligned}
& \tau^{F N}-\tau^{F C}=\left(1+2 \mu_{r}\right)\left(4-t+4 \mu_{r}-2 t \mu_{r}\right) b k_{m}-\left(1+\mu_{r}\right)^{2}(4-t) b k_{m}=\mu_{r}\left(\mu_{r}(4-3 t)\right. \\
& +(4-2 t)) b k_{m}>0, \\
& \quad \tau^{F N}-\tau^{F C}=\left(1+2 \mu_{r}\right)\left(4-t+4 \mu_{r}-2 t \mu_{r}\right) b k_{m}-\left(1+\mu_{r}\right)^{2}(4-t) b k_{m}=\mu_{r}\left(\mu_{r}(4-3 t)\right. \\
& +(4-2 t)) b k_{m}>0 \text {,so } \tau^{F C}<\tau^{F N} \text {. The proofs of } q^{F C}<q^{F N}, w^{F C}<w^{F N} \text { and } \\
& U_{m}^{F C}<U_{m}^{F N} \text { are similar. }
\end{aligned}
$$

\section{Appendix E. Proof of Conclusion 2}

The proofs of $\frac{\partial w^{C S}}{\partial \beta}>0, \frac{\partial \tau^{C S}}{\partial \beta}>0, \frac{\partial q^{C S}}{\partial \beta}>0$ are similar to Proposition 1. In addition, we can also subtly prove that $\frac{\partial C S^{C S}}{\partial \beta}=\frac{\partial C S^{C S}}{\partial q^{C S}} \cdot \frac{\partial q^{C S}}{\partial \beta}=b q^{C S} \cdot \frac{\partial q^{C S}}{\partial \beta}>0$ and $\frac{\partial W^{C S}}{\partial \beta}=\frac{\partial W^{C S}}{\partial q^{C S}} \cdot \frac{\partial q^{C S}}{\partial \beta}=\left(a-b q^{C S}+l \tau\right) \cdot \frac{\partial q^{C S}}{\partial \beta}>0$.

\section{References}

1. Bai Q, Chen M, Xu L. (2017), "Revenue and promotional cost-sharing contract versus two-part tariff contract in coordinating sustainable supply chain systems with deteriorating items",International Journal of Production Economics, Vol.187, pp. 85-101.

2. Banerjee S, Lin P. (2001), “Vertical research joint ventures”,International Journal of Industrial Organization, Vol.19(No. 1), pp. 285-302.

3. Bonini S, Oppenheim J. (2008), "Cultivating the green consumer", Stanford Social Innovation Review, Vol.6 (No. 4), pp. 56-61.

4. Bruyn A D, Bolton G E. (2008), "Estimating the influence of fairness on bargaining behavior”, Management Science, Vol.54 (No. 10), pp. 1774-1791. 
5. Caliskan-Demirag O, Chen Y F, Li J. (2010), "Channel coordination under fairness concerns and nonlinear demand", European Journal of Operational Research, Vol.207 (No. 3), pp. 1321-1326.

6. Carter C R, Jennings M M. (2002), "Social responsibility and supply chain relationships", Transportation Research Part E: Logistics and Transportation Review, Vol.38 (No. 1), pp. 37-52.

7. Chitra K. (2007), "In search of the green consumers: a perceptual study", Journal of Services Research, Vol.7 (No. 1), pp. 173-191.

8. Conrad K. (2005), "Price competition and product differentiation when consumers care for the environment", Environmental and Resource Economics, Vol.31 (No. 1), pp. 1-19.

9. Cruz J M. (2008), "Dynamics of supply chain networks with corporate social responsibility through integrated environmental decision-making", European Journal of Operational Research, Vol.184 (No. 3), pp. 1005-1031.

10. Cruz J M, Wakolbinger T. (2008),"Multiperiod effects of corporate social responsibility on supply chain networks, transaction costs, emissions, and risk",International Journal of Production Economics, Vol.116 (No. 1), pp. 61-74.

11. Cui T H, Raju J S, Zhang Z J. (2007), "Fairness and channel coordination",Management Science, Vol.53(No. 8), pp. 1303-1314.

12. Deng Y, You D, Zhang Y. (2021), "Research on improvement strategies for lowcarbon technology innovation based on a differential game: The perspective of tax competition", Sustainable Production and Consumption, Vol.26, pp. 10461061.

13. Ding C, Wang K, Lai S. (2013), "Channel coordination mechanism with retailers having fairness preference — an improved quantity discount mechanism”, Journal of Industrial and Management Optimization, Vol.9 (No. 4), pp. 967-982.

14. Du S, Nie T, Chu C, Yu Y. (2014), "Newsvendor model for a dyadic supply chain with Nash bargaining fairness concerns",International Journal of Production Research, Vol.52(No. 17), pp. 5070-5085.

15. Fehr E, Klein A, M. S K. (2007), "Fairness and contract design”, Econometrica, Vol.75 (No. 1), pp. 121-154.

16. Fehr E, Schmidt K M. (1999), "A theory of fairness, competition, and cooperation", The Quarterly Journal of Economics, Vol.114 (No. 3), pp. 817-868.

17. Ghosh D, Shah J. (2015), "Supply chain analysis under green sensitive consumer demand and cost sharing contract", International Journal of Production Economics, Vol.164, pp. 319-329.

18. Goering G E. (2008), "Socially concerned firms and the provision of durable goods", Economic Modelling, Vol.25 (No. 3), pp. 575-583.

19. Grimmer M, Bingham T. (2013), "Company environmental performance and consumer purchase intentions", Journal of Business Research, Vol.66 (No. 10), pp. 1945-1953.

20. He P, He Y, Victor Shi C, Xu H, Zhou L. (2020), “Cost-sharing contract design in a low-carbon service supply chain”, Computers \& Industrial Engineering,Vol.139, Article 106160.

21. Ho T H, Su X. (2009), "Peer-Induced Fairness in Games", American Economic Review, Vol.99 (No. 5), pp. 2022-2049.

22. Ho T H, Su X, Wu Y. (2014), “Distributional and peer-induced fairness in supply 
chain contract design",Production and Operations Management, Vol.23(No. 2), pp. 161-175.

23. Ho T H, Zhang J. (2008), "Designing pricing contracts for boundedly rational customers: does the framing of the fixed fee matter?" Management Science, Vol.54(No. 4), pp. 686-700.

24. Jeuland A P, Shugan S M. (1983), "Managing channel profits", Marketing Science, Vol.2 (No. 3), pp. 239-272.

25. Katok E, Pavlov V. (2013), "Fairness in supply chain contracts: A laboratory study", Journal of Operations Management, Vol.31 (No. 3), pp. 129-137.

26. Katok E, Wu D Y. (2009), "Contracting in Supply Chains: A Laboratory Investigation", Management science, Vol.55 (No. 12), pp. 1953-1968.

27. Kumar Jena S, Sarmah S P. (2014), "Price competition and co-operation in a duopoly closed-loop supply chain", International Journal of Production Economics, Vol.156, pp. 346-360.

28. Lash J, Wellington F. (2007), "Competitive advantage on a warming planet", Harvard Business Review, Vol.85 (No. 3), pp. 94-143.

29. Li Q, Xiao T, Qiu Y. (2018),"Price and carbon emission reduction decisions and revenue-sharing contract considering fairness concerns",Journal of Cleaner Production, Vol.190, pp. 303-314.

30. Liu L, Li F. (2020), "Differential game modelling of joint carbon reduction strategy and contract coordination based on low-carbon reference of consumers", Journal of Cleaner Production, Vol.277, Article 123798.

31. Liu Z L, Anderson T D, Cruz J M. (2012), "Consumer environmental awareness and competition in two-stage supply chains", EuropeanJournal of Operational Research, Vol.218 (No. 3), pp. 602-613.

32. Moorthy K S. (1987), "Managing channel profits: comment source", Marketing Science, Vol.6 (No. 4), pp. 375-379.

33. Ni D, Li K W, Tang X. (2012),"A game-theoretic analysis of social responsibility conduct in two-echelon supply chains", International Journal of Production Economics, Vol.138(No. 2), pp. 303-313.

34. Nidumolu R, Prahalad C K, Rangaswami M R. (2009), "Why sustainability is now the key driver of innovation",Harvard Business Review, Vol.87(No. 9), pp. 56-64.

35. Nie T, Du S. (2017), "Dual-fairness supply chain with quantity discount contracts", European Journal of Operational Research, Vol.258 (No. 2), pp. 491500.

36. Pan K, Cui Z, Xing A, Lu Q. (2020), "Impact of fairness concern on retailerdominated supply chain",Computers \& Industrial Engineering, Vol.139, Article 106209.

37. Panda S. (2014), "Coordination of a socially responsible supply chain using revenue sharing contract", Transportation Research Part E: Logistics and Transportation Review, Vol.67, pp. 92-104.

38. Pu X, Gong L, Han G. (2019), “A feasible incentive contract between a manufacturer and his fairness-sensitive retailer engaged in strategic marketing efforts",Journal of Intelligent Manufacturing, Vol.30(No. 1), pp. 193-206.

39. Rao P. (2002), "Greening the supply chain: a new initiative in South East Asia", International Journal of Operations \& Production Management, Vol.22 (No. 6), 
pp. 632-655.

40. Ray S, Jewkes E M. (2004), "Customer lead time management when both demand and price are lead time sensitive", European Journal of Operational Research, Vol.153 (No. 3), pp. 769-781.

41. Robert D. Klassen C P M. (1996), "The impact of environmental management on firm performance", Management Science, Vol.42 (No. 8), pp. 1199-1214.

42. Seuring S. (2013), "A review of modeling approaches for sustainable supply chain management”, Decision Support Systems, Vol.54 (No. 4), pp. 1513-1520.

43. Seuring S, Müller M. (2008), "From a literature review to a conceptual framework for sustainable supply chain management", Journal of Cleaner Production, Vol.16 (No. 15), pp. 1699-1710.

44. Shen B, Ding X, Chen L, Chan H L. (2017), "Low carbon supply chain with energy consumption constraints: case studies from China's textile industry and simple analytical model",Supply Chain Management, Vol.22(No. 3), pp. 258-269.

45. Spengler J J. (1950), "Vertical integration and antitrust policy". Journal of Political Economy, Vol.58 (No. 4), pp. 347-352.

46. Taleizadeh A A, Alizadeh-Basban N, Sarker B R. (2018), “Coordinated contracts in a two-echelon green supply chain considering pricing strategy",Computers \& Industrial Engineering, Vol.124, pp. 249-275.

47. Trudel R, Cotte J. (2009), “Does it pay to be good?”,MIT Sloan Management Review, Vol.50(No. 2), pp. 61-68.

48. Wang Q, Zhao D, He L. (2016), “Contracting emission reduction for supply chains considering market low-carbon preference", Journal of Cleaner Production, Vol.120, pp. 72-84.

49. Wang Y, Yu Z, Jin M, Mao J. (2021), "Decisions and coordination of retailer-led LCSC under altruistic preference", European Journal of Operational Research, Vol.293 (No. 3), pp. 910-925.

50. Xiao Q, Chen L, Xie M, Wang C. (2020), “Optimal contract design in sustainable supply chain: Interactive impacts of fairness concern and overconfidence", The Journal of the Operational Research Society, Vol. 72(No, 7), pp. 1505-1524.

51. Yang F, Shan F, Jin M. (2017), "Capacity investment under cost sharing contracts", International Journal of Production Economics, Vol.191, pp. 278-285.

52. Zhang C, Liu L. (2013),"Research on coordination mechanism in three-level green supply chain under non-cooperative game",Applied Mathematical Modelling, Vol.37(No. 5), pp. 3369-3379.

53. Zhang Z, Yu L. (2021), "Dynamic optimization and coordination of cooperative emission reduction in a dual-channel supply chain considering reference lowcarbon effect and low-carbon goodwill", International Journal of Environmental Research and Public Health, Vol.18 (No. 2), pp. 539.

54. Zheng X, Liu Z, Li K W, Huang J, Chen J. (2019), “Cooperative game approaches to coordinating a three-echelon closed-loop supply chain with fairness concerns", International Journal of Production Economics, Vol.212, pp. 92-110.

55. Zhou Y, Bao M, Chen X, Xu X. (2016),“Co-op advertising and emission reduction cost sharing contracts and coordination in LCSC based on fairness concerns",Journal of Cleaner Production, Vol.133, pp. 402-413. 


\section{Acknowledgement}

This work was supported by the National Natural Science Foundation of China under grant number 71972094.

\section{About Our Authors}

Li-Hong He is a Professor of Supply Chain Management at the School of Management, Lanzhou University, China. She received her BSc degree in applied mathematics in 1989, her master's degree in computational mathematics in 1999, and Ph.D. in solid mechanics in 2005, all from Lanzhou University, China. She has taught courses on Data, Model and Decisions to MBAs, and Operations Research and Statistics to undergraduates at the School of Management, Lanzhou University. Her research interests are currently focused on pricing and advertising strategies, supply chain management, operations research, and applied statistics.

Yong-Kang Leng is a graduate student in the School of Management, Lanzhou University, and his main research interests are sustainable supply chain and closedloop supply chain.

Sheng-Nan Pan received her master's degree in business management in 2020 from Lanzhou University. Now sheis an assistant at Jiaozuo University with a focus on low carbon supply chain. 